\title{
BNREL
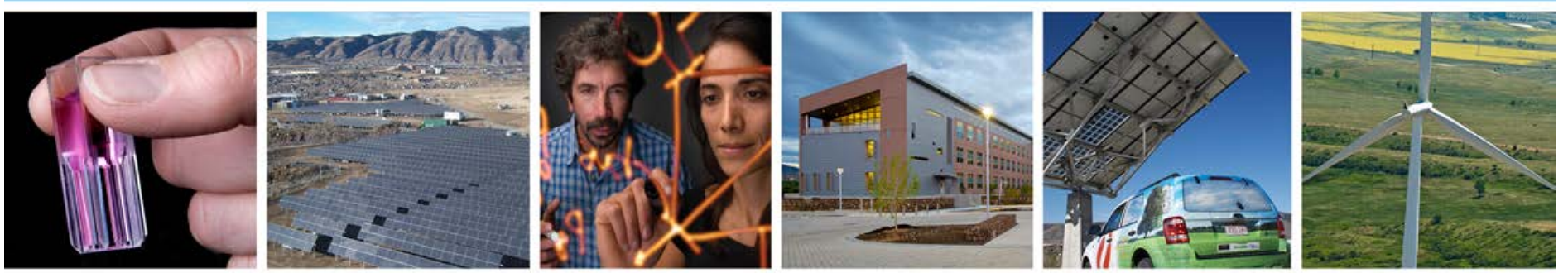

\section{Permanent Magnet Synchronous Condenser for Wind Power Plant Grid Connection Support}

\section{Preprint}

P. Hsu

San Jose State University

E. Muljadi

National Renewable Energy Laboratory

To be presented at the IEEE $20159^{\text {th }}$ International Conference on Power Electronics (ICPE 2015-ECCE Asia)

Seoul, Korea

June 1-5, 2015

NREL is a national laboratory of the U.S. Department of Energy Office of Energy Efficiency \& Renewable Energy

Operated by the Alliance for Sustainable Energy, LLC

This report is available at no cost from the National Renewable Energy Laboratory (NREL) at www.nrel.gov/publications.

\section{Conference Paper}

NREL/CP-5D00-63734

April 2015

Contract No. DE-AC36-08GO28308 


\section{NOTICE}

The submitted manuscript has been offered by an employee of the Alliance for Sustainable Energy, LLC (Alliance), a contractor of the US Government under Contract No. DE-AC36-08GO28308. Accordingly, the US Government and Alliance retain a nonexclusive royalty-free license to publish or reproduce the published form of this contribution, or allow others to do so, for US Government purposes.

This report was prepared as an account of work sponsored by an agency of the United States government. Neither the United States government nor any agency thereof, nor any of their employees, makes any warranty, express or implied, or assumes any legal liability or responsibility for the accuracy, completeness, or usefulness of any information, apparatus, product, or process disclosed, or represents that its use would not infringe privately owned rights. Reference herein to any specific commercial product, process, or service by trade name, trademark, manufacturer, or otherwise does not necessarily constitute or imply its endorsement, recommendation, or favoring by the United States government or any agency thereof. The views and opinions of authors expressed herein do not necessarily state or reflect those of the United States government or any agency thereof.

This report is available at no cost from the National Renewable Energy Laboratory (NREL) at www.nrel.gov/publications.

Available electronically at http://www.osti.gov/scitech

Available for a processing fee to U.S. Department of Energy and its contractors, in paper, from:

U.S. Department of Energy

Office of Scientific and Technical Information

P.O. Box 62

Oak Ridge, TN 37831-0062

phone: 865.576.8401

fax: 865.576 .5728

email: mailto:reports@adonis.osti.gov

Available for sale to the public, in paper, from:

U.S. Department of Commerce

National Technical Information Service

5285 Port Royal Road

Springfield, VA 22161

phone: 800.553 .6847

fax: 703.605.6900

email: orders@ntis.fedworld.gov

online ordering: http://www.ntis.gov/help/ordermethods.aspx 


\section{Permanent Magnet Synchronous Condenser for Wind Power Plant Grid Connection Support}

\author{
Ping Hsu \\ San Jose State University \\ San Jose, California, USA
}

\author{
Eduard Muljadi \\ National Renewable Energy Lab \\ Golden, Colorado, USA
}

\begin{abstract}
A synchronous condenser (SC) using a permanent magnet synchronous generator (PMSG) is proposed for providing necessary reactive power to a wind power plant to support its connection to a weak grid. A PMSG has the advantage of higher efficiency and reliability. Because of its lack of a field winding, a PMSG is typically controlled by a full-power converter, which can be costly. In the proposed system, the reactive power of the $\mathrm{SC}$ is controlled by a serially connected compensator operating in a closed-loop configuration. The compensator also damps the PMSG's tendency to oscillate. The compensator's VA rating is only a fraction of the rating of the $\mathrm{SC}$ and the PMSG. In this initial investigation, the proposed scheme is shown to be effective by computer simulations.
\end{abstract}

Index Terms-Wind power plant, grid connection, synchronous condenser, permanent magnet synchronous machine, reactive power control, voltage stabilization.

\section{INTRODUCTION}

High impedance of a weak grid connection limits the output power of a wind power plant operating at unity power factor. This limitation can be alleviated by sufficiently high VAR support. Although it is possible for wind turbine generators to produce the necessary VAR, this approach can substantially increase the VA rating requirement (and hence the cost) of the wind generators and control inverters. Synchronous condensers (SCs) have been used traditionally in the power industry to support weak grids that have poor voltage regulation. Static equipment such as static synchronous compensators (STATCOMs) and static VAR compensators (SVCs) [1] are now often used for reactive power production. SVCs and STATCOMs have the advantage of faster responses [2]. Under certain grid fault conditions [3], SCs provide higher reactive power, and, more importantly, the kinetic energy stored in the rotor provides inertial support to the grid during faults [4]. The inertia support capability and fast response time become more important as the grid-connection requirements (such as low-voltage ride-through) for distributed generation become more stringent and wind turbines are required to provide ancillary services to support grid stability.

The proposed VAR compensation scheme utilizes a PMSGbased SC instead of a wound-field machine as in a traditional $\mathrm{SC}$. The control of VAR output from the proposed SC is achieved by a series compensator connected to the PMSG. This compensator also damps the PMSG's tendency to oscillate when connected to an AC source [5]. A crowbar circuit should be used to protect the power electronics of the compensator circuit during a grid fault.

\section{THEORY OF OPERATION OF THE PROPOSED REACTIVE POWER CONTROL}

\subsection{Power Transmission Limitation}

Fig. 1 shows a model of a WPP connected to a weak grid. $V_{G}$ and $V_{L}$ in the figure represent the voltage at the infinite bus and at the point of interconnection (POI) of the WPP, respectively. $R$ and $j X$ represent the transmission line impedance. Note that in most cases the transmission line resistance is often considered negligible. In weak grids, the impedance is often five to ten times higher than strong grids.

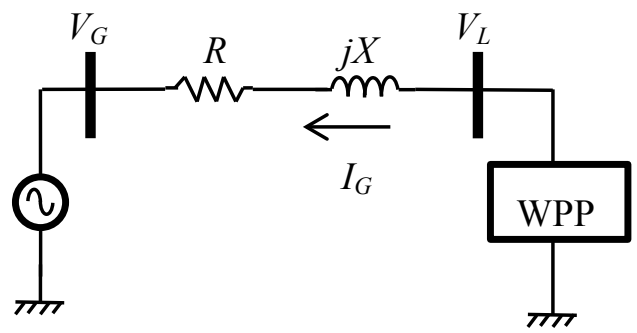

Fig. 1. A wind power plant connected to a weak grid.

The current $I_{G}$ in Fig. 1 can be expressed as in (1).

$$
I_{G}=\frac{V_{L}-V_{G}}{R+j X}
$$

Consider a WPP that operates at unity power factor. The current, $I_{G}$, is in phase with the voltage, $V_{L}$, as in (2), and in this case the WPP output power is given in (3).

$$
\begin{aligned}
& \angle I_{G}=\angle V_{L} \\
& P=3|I|\left|V_{L}\right|
\end{aligned}
$$

The relationships between the WPP POI voltage, $V_{L}$, and the WPP output power, $P$, can be derived from (1), (2), and (3). Fig. 2 shows this relationship for the case $V_{G}=12 \mathrm{kv}, X=$ $11.31 \Omega$ (line inductance $=30 \mathrm{mH}$ ), and $R=0.01 \Omega$. As shown, in this case the maximum power transmission is approximately $6.5 \mathrm{MW}$, and it is achieved with the WPP connection voltage drop to approximately $70 \%$ of the nominal voltage, which, of course, is not acceptable.

\subsection{Reactive Power Control}

Fig. 3 shows the configuration of the proposed PMSG-based SC. As shown, the controller's output voltage is connected in series to the phase windings of the PMSG through 
transformers. It is possible to directly connect the compensator output in series to the PMSG (without the transformers) if the inverter circuit in the compensator is properly designed. The connection can also be made on the grid side if the common point of the PMSG's Y-connection cannot be accessed and separated. In this case, the direct connection to the compensator inverter circuit would be difficult because of the high voltage and lack of a common voltage reference point.

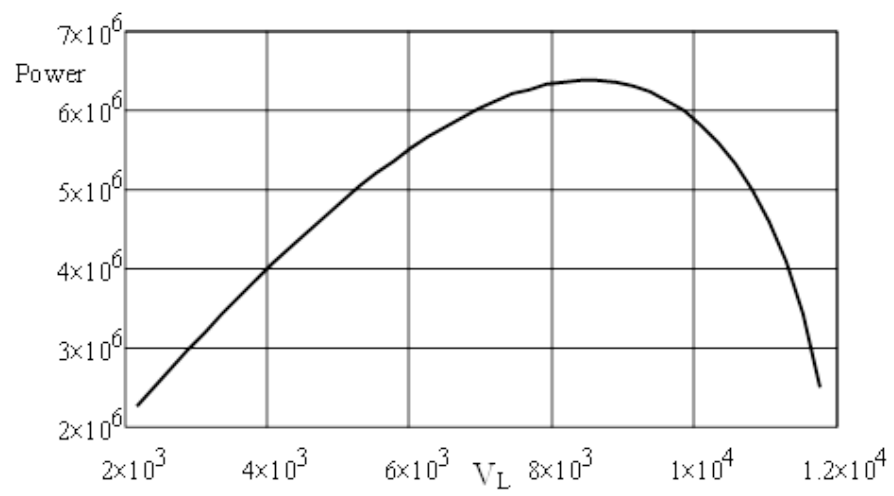

Fig. 2. Power $(\mathrm{P})$ transmission via a transmission line compared to voltage at the WPP connection $\left(V_{L}\right)$.

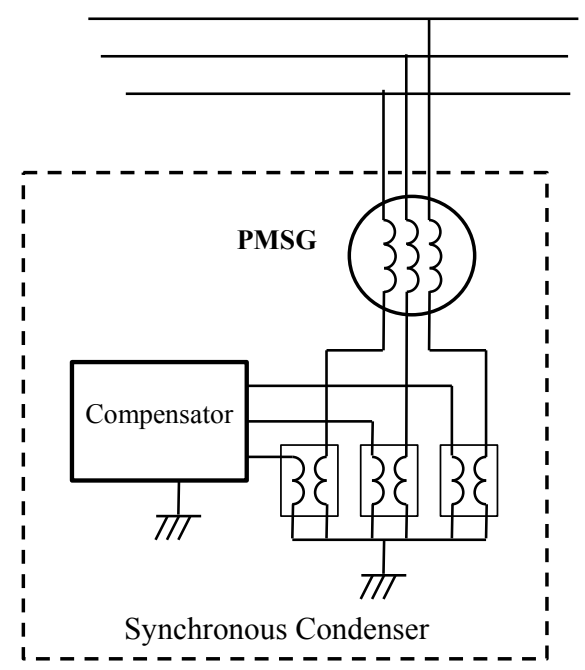

Fig. 3. Configuration of the proposed synchronous condenser.

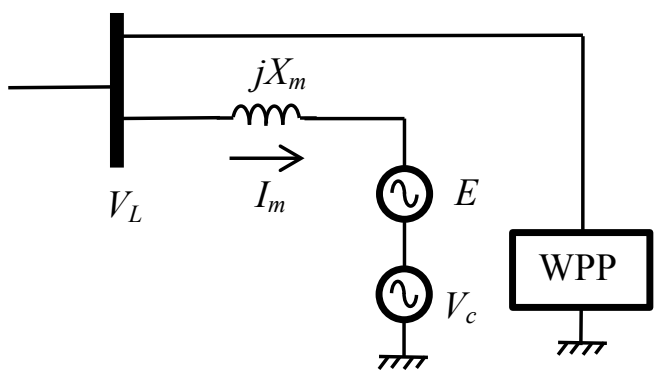

Fig. 4. Equivalent circuit of the configuration shown in Fig. 1.

Fig. 4 shows the equivalent circuit of the $\mathrm{SC}$ with the series compensator, where $V_{c}$ represents the compensator output voltage, $E$ represents the voltage from the internal emf of the PMSG, and $X_{m}$ is the PMSG's impedance.
The compensator output voltage, $V_{c}$, is controlled to be inphase with $V_{L}$ via a phase-locked loop. Also, the PMSG has no mechanical loading. Under such conditions, all three voltages - $V_{L}, V_{c}$, and $E$ - are in phase. In this case, if $V_{c}$ is positively in phase with $E$ and $\left|V_{c}\right|$ is high enough such that $V_{c}+E>V_{L}$, the effect is the same as a synchronous woundfield machine that is overexcited and provides VAR to the grid. If, on the other hand, $V_{c}$ is 180 degrees out of phase with $E$ and $\left|V_{c}\right|$ is high enough such that $V_{c}+E<V_{L}$, the effect is the same as a synchronous machine that is underexcited and absorbs VAR from the grid. This operation is described by equation (4) and (5) below. The current $I_{m}$ in this circuit is given by (4), and the complex power drawn by the $\mathrm{SC}$ is given in (5), where the superscript asterisk represents complexconjugate operation.

$$
\begin{gathered}
I_{m}=\frac{V_{L}-\left(E+V_{C}\right)}{j X_{m}} \\
S=V_{L} \cdot I_{m}^{*}=V_{L}\left(\frac{V_{L}-\left(E+V_{C}\right)}{j X_{m}}\right)^{*}
\end{gathered}
$$

Under the condition that all three voltages $-V_{L}, V_{c}$, and $E-$ are in phase, the complex power, $S$, given by (5) is pure imaginary. In other words, this subsystem only produces or consumes VARs and the amount of VARs can be controlled by the signed magnitude of the compensator output voltage, $V_{c}$.

In normal operating conditions, the value of $E$ in (5) remains nearly constant, because the PMSG's speed only slightly fluctuates about the synchronous speed, and $E$, by design, matches the nominal voltage of $V_{L}$. Under this condition, the compensator output, $V_{c}$, can be varied to produce the necessary reactive power to support a WPP for a weak grid connection.

\subsection{Damping Control}

Equation (6) is the control law [5] for damping the PMSG's tendency of oscillation when directly connected to the grid. The following nomenclatures are used in (6).

$L_{m}$
$R_{m}$
$v_{q c}, v_{d c}$
$\omega, \omega_{\text {sync }}$
$\varepsilon$
$k_{b}$

: PMSG inductance

: Resistance of the stator windings

: $\mathrm{q}$ and $\mathrm{d}$ axis voltage of the compensator

: generator mechanical speed and sync speed

: a small number for the pseudo-differentiator

: damping constant

$$
\left[\begin{array}{c}
v_{d c}(s) \\
v_{q c}(s)
\end{array}\right]=\left[\begin{array}{c}
-\omega L_{m} \\
\frac{L_{m} s}{\varepsilon s+1}+R_{m}
\end{array}\right] k_{b}\left(\omega_{s y n c}-\omega\right)
$$

The implementation of the damping control law (6) requires two additional transformation operations: a transformation from a dq frame to a synchronous frame and a transformation from two-phase to three-phase, as shown in Fig. 5 [5]. $V_{D}$ in 
Fig. 5 is the result from these transformations. $V_{D}$ and a reactive power control voltage (described in the following section) constitute the compensator output voltage.

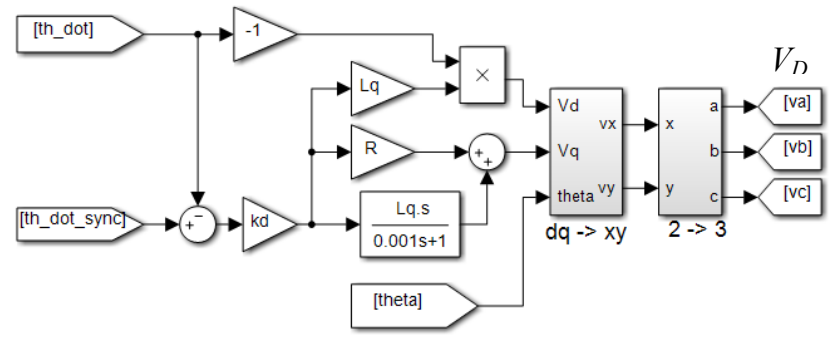

Fig. 5. The damping control implementation diagram.

\section{VAR COMPENSATION CONTROLLER}

The main objective of the compensator is to control the production of reactive power that is necessary to maintain the voltage $V_{L}$ at the nominal value. This is done by controlling the compensator output, $V_{c}$, according to a PI controller, as shown in (6). The phase of $V_{c}$ is locked to the phase of $V_{L}$. The secondary control objective is to produce the damping effect to damp the oscillation of the PMSG, as explained earlier.

$$
\left|V_{c}\right|=\left(k_{p}+\frac{k_{i}}{s}\right)\left(V_{\text {ref }}-\left|V_{L}\right|\right)
$$

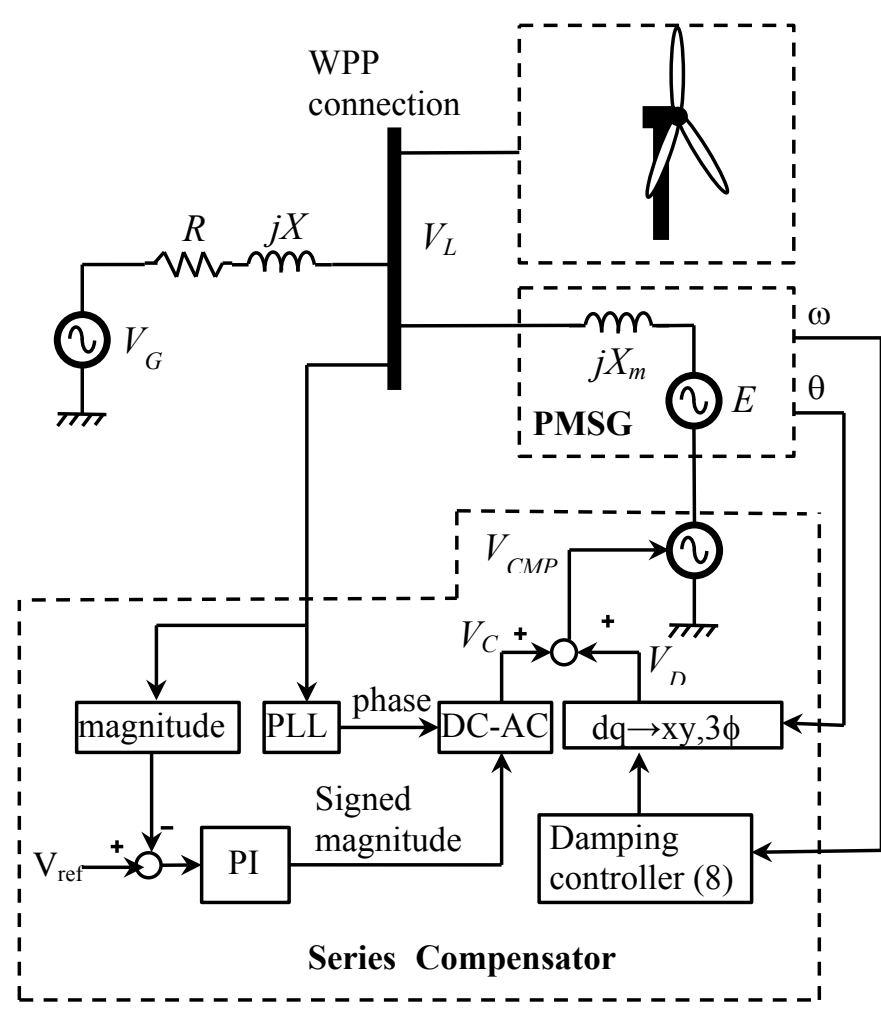

Fig. 6. A block diagram of the overall system.

The output voltage of the compensator $\left(V_{C M P}\right)$ is the sum of the voltage $V_{c}$ and the damping control output, as given in (6) and Fig. $5\left(V_{D}\right)$. Fig. 6 is a functional block diagram of the overall VAR compensation control system. This block diagram includes an infinite bus of voltage $V_{G}$, transmission line dynamics ( $R$ and $j X), \mathrm{WPP}$, and the SC (i.e., the PMSG) with the series compensator. The diagram also includes the structure of the damping control and the VAR control algorithm. $V_{\text {ref }}$ in the figure is the reference voltage for the WPP voltage control. A phase-locked loop is used to synchronize the phase of the WPP connection voltage and that of the compensator output voltage.

\section{Simulation RESUlts}

The computer simulation model is created based on the block diagram shown in Fig. 6. Following are the values of some of the key parameters used in the simulation.

Line voltage: $12 \mathrm{kV}$

Transmission line resistance: $0.01 \Omega$.

Transmission line inductance: $30 \mathrm{mH}$

PMSG inductance: $4 \mathrm{mH}$

PMSG resistance: $0.05 \Omega$

Results from several simulation runs are shown in this section. In all the simulation runs, the power from the WPP is initially set to 0 , and at $3 \mathrm{~s}$ it is ramped up to $10 \mathrm{MW}$ (p.f. $=1$ at $12 \mathrm{kv}$ ) in $2 \mathrm{~s}$. At $\mathrm{t}=10 \mathrm{~s}$, the power is ramped back down to 0 in $2 \mathrm{~s}$. As explained earlier, the output power from the WPP can be restricted by the transmission line if the grid is weak ( $\mathrm{X}$ is large). Between $5 \mathrm{~s}$ and $10 \mathrm{~s}$, the WPP attempts to deliver 10 $\mathrm{MW}$, but this is not achieved in some of the simulation runs.
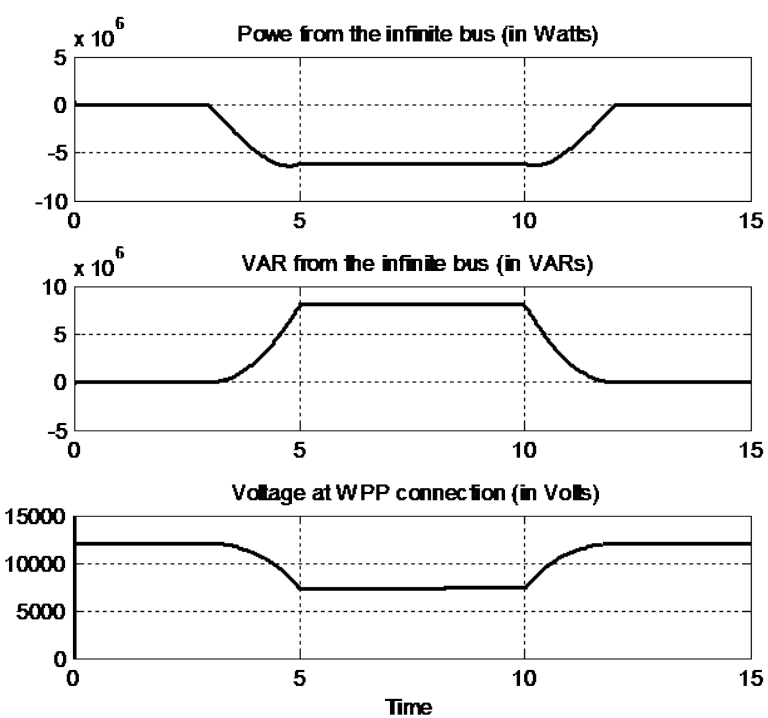

Fig. 7. Results from Simulation \#1 (no SC is used): power from the infinite bus, VAR from the finite bus, and the voltage at the WPP POI.

Fig. 7 shows the results from the first simulation run, in which the proposed SC is not used. The transmission line inductance is set to $30 \mathrm{mH}$. The first and the second traces in this figure are the power and reactive power drawn from the infinite bus. The third trace is the voltage at the WPP connection, i.e., the RMS value of phase-to-phase voltage of $V_{L}$. As shown, as the output of the power is injected into the WPP connection, the voltage drops. In this case, the power only reached about 6 
MW The voltage at the WPP connection drops to about $7 \mathrm{kV}$. This result agrees with the analytical results shown in Fig. 2.

Fig. 8 and Fig. 9 show simulation results from the second run, which has the same condition as the first except that the proposed SC is used. Traces in Fig. 8 correspond to those in Fig. 7. Fig. 8 shows that, with the SC, the output power from the WPP can reach $10 \mathrm{MW}$ and the operation is stable. As shown by the third trace, the voltage at the WPP connection is kept nearly constant at the nominal value. The initial transient is due to the initial condition of the simulation model.
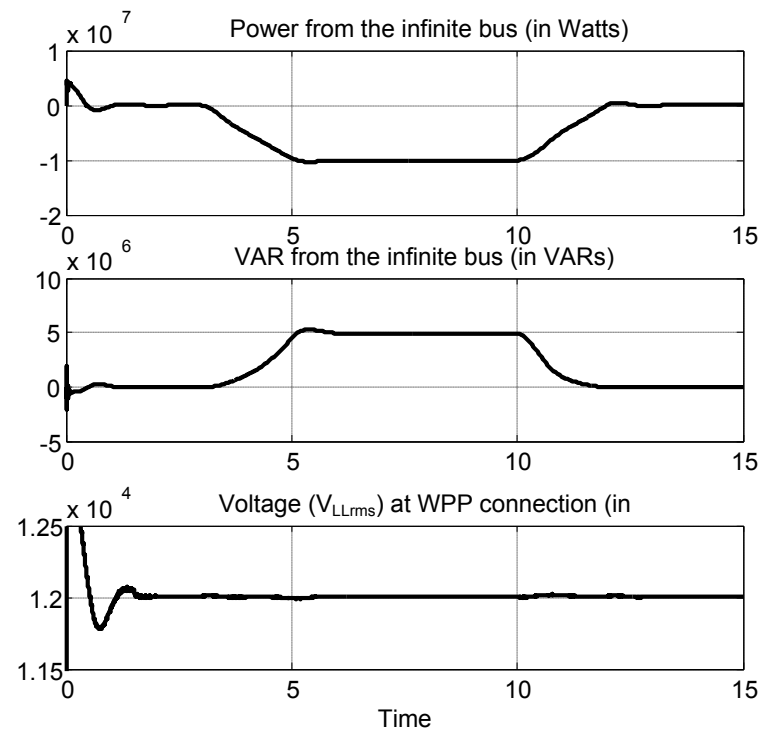

Fig. 8. Results from Simulation run \#2 ( $\mathrm{SC}$ is used): power from the infinite bus, VAR from the infinite bus, and the voltage at the WPP connection.
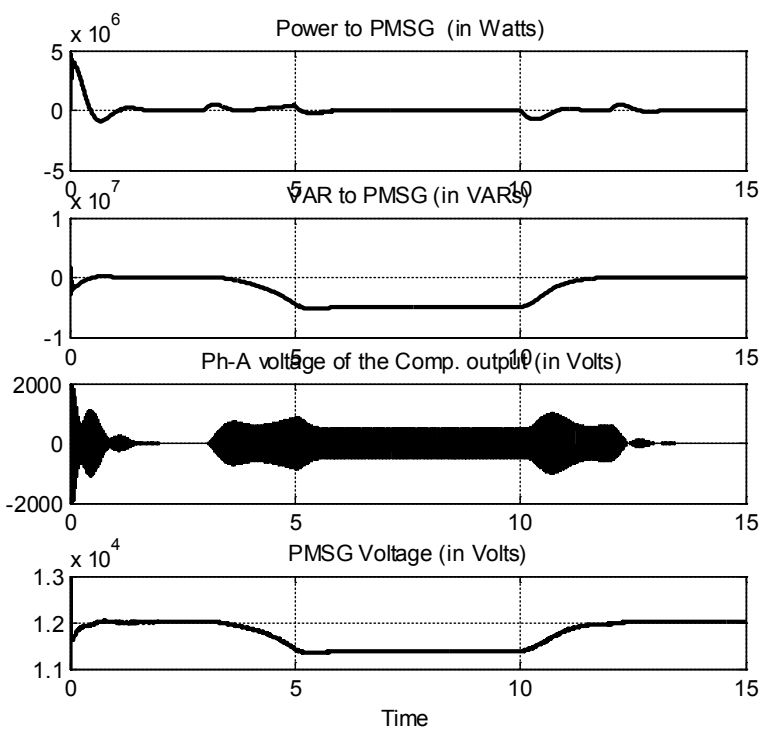

Fig. 9. Results from Simulation \#2 (SC is used): power to the PMSG, VAR to the PMSG, phase-A output voltage of the compensator, and the line voltage of the PMSG.

The traces shown in Fig. 9 are the power and VAR delivered to the $\mathrm{SC}$ and the compensator output voltage, and the PMSG phase voltage. These traces are generated from the same simulation run as that shown in Fig. 8. The first trace in Fig. 9 shows that SC does not deliver or consume real power. The second trace shows that the SC provides approximately 5 MVar reactive power to the WPP connection. This amount is the same as the reactive power provided by the infinite bus. The third trace is the output voltage from the compensator ( $V_{C M P}$ in Fig. 6). As shown, the peak value is approximately 1 $\mathrm{kV}$, which is about only $10 \%$ of the phase voltage of the system. This shows that the VA rating of the compenstor is approximately $10 \%$ of the rating of the SC. The last trace in Fig. 9 shows the PMSG's phase voltage. This voltage is lower than the nominal value because of the voltage across the compensator.

To demonstrate the effectiveness of the damping control, in the third simulation run, the damping control portion of the SC is disabled. The result of this simulation is shown in Fig. 10, where the traces correspond to those in Fig. 8. As shown, the system oscialltes at a sub-synchonous frequency. This is because of the lack of mechanical damping and the interaction between the PMSG rotor inertia and the electromagnetic torque as affected to the load angle.
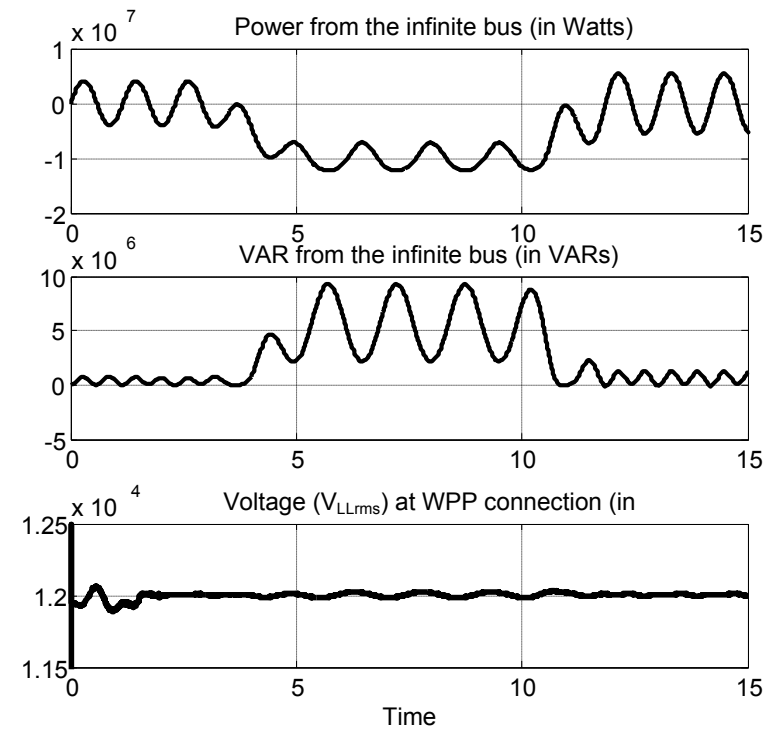

Fig. 10. All traces correspond to those in Fig. 8. In this simulation, the damping control function of the compensator is disabled.

Two additional simulations are performed. These simulations are performed in the same condition as the condition that generated Fig. 7 and Fig. 8 (i.e., Simulation Run \#1 and \#2), except that the transmission line inductance is increased to 50 $\mathrm{mH}$ and only $7.5 \mathrm{MW}$ is attempted by the WPP. Fig. 11 and Fig. 12 show the results from these two simulation runs. As shown in Fig. 11 (where no SC is used), the power limit is further reduced to under $2 \mathrm{MW}$ from $6 \mathrm{MW}$ as in Fig. 7 because of the higher line inductance. Fig. 12 shows that with the VAR support from the SC, a higher real power (7.5 MW) can be transmitted. Simulations show that attempting to transmit more than $8 \mathrm{MW}$ in this case can cause the voltage crash, even with the compensator online. 

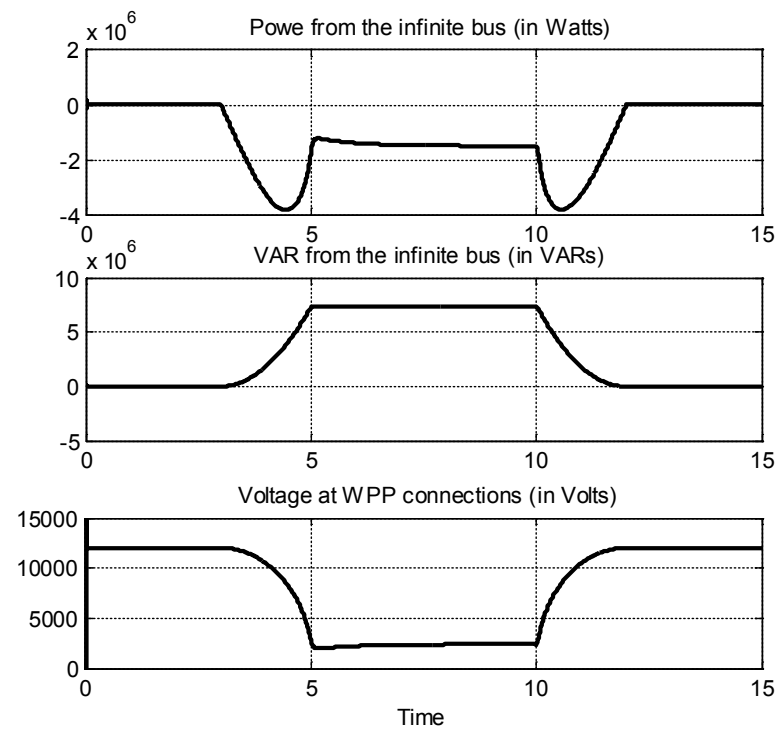

Fig. 11 Results from Simulation Run \#4 (SC is not used). All traces correspond to those in Fig. 7.
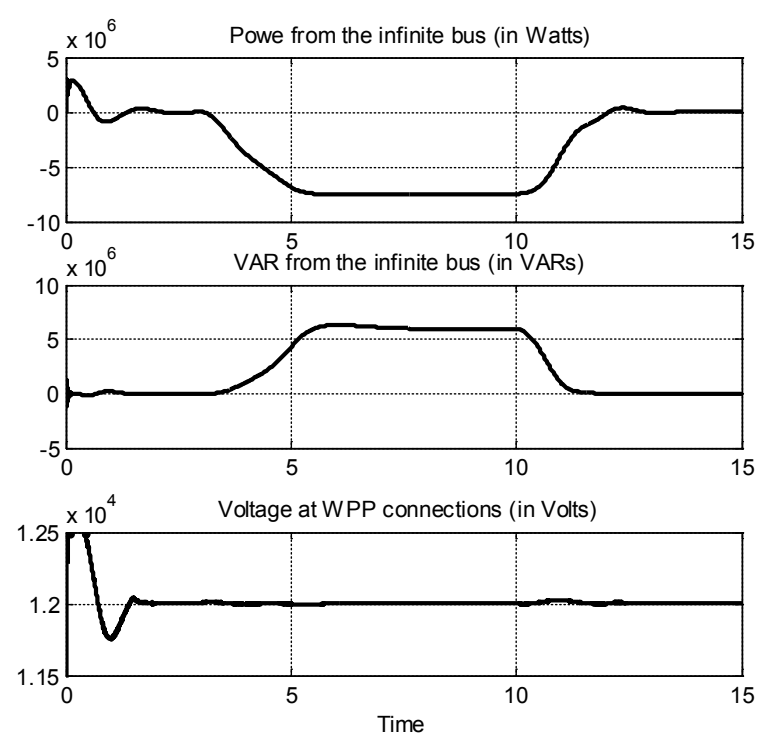

Fig. 12. Results from Simulation Run \#5. All traces correspond to those in Fig. 8. SC is used in this simulation.

\section{CONCLUSION}

In this paper, we propose using a PMSG instead of a woundfield machine for SCs to support WPPs connected to a weak grid. The control of the reactive power is achieved by a serially connected converter that can react to the grid condition faster than that of a wound-field machine and has a VA rating that is only a fraction of the rating of the SC.

An SC has the advantage over a STATCOM or SVC by being able to provide real power in a grid fault condition (provided by the rotating mass-inertial response). The proposed scheme is shown to be effective based on the preliminary study we have performed.

\section{ACKNOWLEDGMENT}

This work was supported by the U.S. Department of Energy under Contract No. DE-AC36-08-GO28308 with the National
Renewable Energy Laboratory and by the San Jose State University, San Jose, California.

\section{REFERENCES}

[1] H. A. Kojori, S. B. Dewan and J. D. Lavers, "A large-scale PWM solid-state synchronous condenser," IEEE Transactions on Industry Applications, vol. 28, no. 1, 1992.

[2] M. F. Soheil Ganjefar, "Comparing SVC and synchronous condenser performacnee in mitigating torsional oscillations," International Transactions on Electrical Energy Systems, vol. Wiley Online Library, 2014.

[3] S. Teleke, T. Abdulahovic, T. Thiringer and J. Svensson, "Dynamic performance comparisonof synchronous condenser and SVC," IEEE Transactions on Power Delivery, vol. 23, no. 3, 2008.

[4] N. Mendis, k. Muttaqi and S. Perera, "Management of batterysupercapacitro hybrid energy storage and synchronous condenser for isolated operation of PMSG-based variable-speed wind turbine generating systems," IEEE Transaction on Smart Grid, vol. 5, no. 2, pp. 944-953, 2014.

[5] P. Hsu and E. Muljadi, "Damping control for permanent magnet synchronous generators and its application in a multi-turbine system." in Australasian Universities Power Engineering Conference, AUPEC, 2014.

[6] D. Novotny and T. Lipo, Vectro Control and Dynamics of AC Drives, Oxford, 1997.

\section{BIOGRAPHIES}

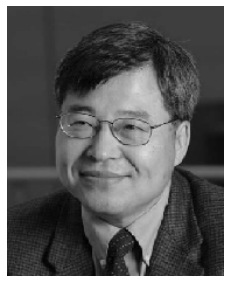

Ping Hsu (M'1990) graduated from the University of California at Berkeley in 1988 with a $\mathrm{Ph} . \mathrm{D}$. in electrical engineering. He joined the Department of Mechanical and Industrial Engineering at the University of Illinois at Urbana-Champaign in 1989, and in 1990 he joined the Department of Electrical Engineering at San Jose State University. At San Jose State University, he served as the associate dean of the College of Engineering from 2001 to 2007 and interim dean from 2012 to 2013. His research interests include control theory, robotics, power electronics, machine control, and renewable energy systems.

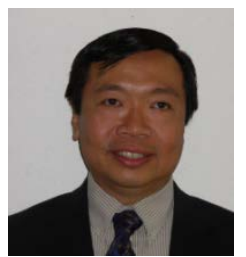

Eduard Muljadi (M'82, SM'94, F'10) received his Ph.D. in electrical engineering from the University of Wisconsin at Madison. From 1988 to 1992 , he taught at California State University at Fresno. In June 1992, he joined the National Renewable Energy Laboratory in Golden, Colorado. His current research interests are in the fields of electric machines, power electronics, and power systems in general with an emphasis on renewable energy applications. He is member of Eta Kappa $\mathrm{Nu}$ and Sigma Xi, a fellow of the Institute of Electrical and Electronics Engineers (IEEE), and an editor of the IEEE Transactions on Energy Conversion. He is involved in the activities of the IEEE Industry Application Society (IAS), Power Electronics Society, and Power and Energy Society (PES). He is currently a member of various committees of the IAS, and a member of the Working Group on Renewable Technologies and the Task Force on Dynamic Performance of Wind Power Generation, both of the PES. He holds two patents in power conversion for renewable energy. 